Atmos. Chem. Phys., 19, 14417-14430, 2019

https://doi.org/10.5194/acp-19-14417-2019

(C) Author(s) 2019. This work is distributed under

the Creative Commons Attribution 4.0 License.

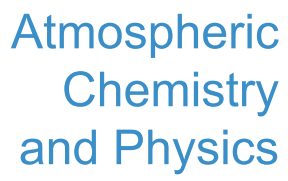

(c) (P)

\title{
One year of aerosol refractive index measurement from a coastal Antarctic site
}

\author{
Zsófia Jurányi $^{1, \mathrm{a}}$ and Rolf Weller ${ }^{1}$ \\ ${ }^{1}$ Alfred-Wegener-Institut Helmholtz Zentrum für Polar- und Meeresforschung, Bremerhaven, Germany \\ ${ }^{a}$ now at: Institute for the Protection of Maritime Infrastructures, German Aerospace Center (DLR), Bremerhaven, Germany
}

Correspondence: Zsófia Jurányi (zsofia.juranyi@gmail.com)

Received: 22 March 2019 - Discussion started: 29 March 2019

Revised: 17 September 2019 - Accepted: 26 October 2019 - Published: 28 November 2019

\begin{abstract}
Though the environmental conditions of the Weddell Sea region and Dronning Maud Land are still relatively stable compared to the fast-changing Antarctic Peninsula, we may suspect pronounced effects of global climate change for the near future (Thompson et al., 2011). Reducing the uncertainties in climate change modeling requires a better understanding of the aerosol optical properties, and for this we need accurate data on the aerosol refractive index (RI). Due to the remoteness of Antarctica only very few RI data are available from this region (Hogan et al., 1979; Virkkula et al., 2006; Shepherd et al., 2018). We calculate the real refractive index of natural atmospheric aerosols from number size distribution measurements at the German coastal Antarctic station Neumayer III. Given the high average scattering albedo of 0.992 (Weller et al., 2013), we assumed that the imaginary part of the RI is zero. Our method uses the overlapping size range (particle diameter $D$ between 120 and $340 \mathrm{~nm}$ ) of a scanning mobility particle sizer (SMPS), which sizes the particles by their electrical mobility, and a laser aerosol spectrometer (LAS), which sizes the particles by their optical scattering signal at the $633 \mathrm{~nm}$ wavelength.

Based on almost a complete year of measurement, the average effective refractive index ( $\mathrm{RI}_{\text {eff }}$, as we call our retrieved RI because of the used assumptions) for the dry aerosol particles turned out to be 1.44 with a standard deviation of 0.08 , in a good agreement with the RI value of 1.47 , which we derived from the chemical composition of bulk aerosol sampling measurements. At Neumayer the aerosol shows a pronounced seasonal pattern in both number concentration and chemical composition. Despite this, the variability of the monthly averaged $\mathrm{RI}_{\text {eff }}$ values remained between 1.40 and 1.50. Compared to the annual mean, two austral win-
\end{abstract}

ter months (July and September) showed slightly but significantly increased values (1.50 and 1.47 , respectively). The size dependency of the $\mathrm{RI}_{\text {eff }}$ could be determined from timeaveraged LAS and SMPS number size distributions measured between December 2017 and January 2018. Here we calculated $\mathrm{RI}_{\text {eff }}$ for four different particle size ranges and observed a slight decrease from 1.47 ( $D$ range $116-168 \mathrm{~nm}$ ) to 1.37 ( $D$ range $346-478 \mathrm{~nm}$ ).

We find no significant dependence of the derived $\mathrm{RI}_{\text {eff }}$ values on the wind direction. Thus we conclude that $\mathrm{RI}_{\text {eff }}$ is largely independent of the general weather situation, roughly classified as (i) advection of marine boundary layer air masses during easterly winds caused by passing cyclones in contrast to (ii) air mass transport from continental Antarctica under southern katabatic winds. Neumayer, the only relevant contamination source, is located $1.5 \mathrm{~km}$ north of the air chemistry observatory, where the measurements were performed. Given that northerly winds are almost absent, the potential impact of local contamination is minimized in general. Indeed our data show no impact of local contamination

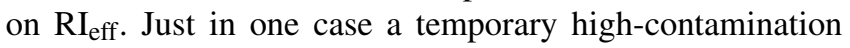
episode with diesel engines operating right next to the measurement site resulted in an unusual high $\mathrm{RI}_{\text {eff }}$ of 1.59 , probably caused by the high black carbon content of the exhaust fumes.

To conclude, our study revealed largely constant $\mathrm{RI}_{\mathrm{eff}}$ values throughout the year without any sign of seasonality. Therefore, it seems reasonable to use a single, constant $\mathrm{RI}_{\mathrm{eff}}$ value of 1.44 for modeling optical properties of natural, coastal Antarctic sub-micrometer aerosol. 


\section{Introduction}

Atmospheric aerosols affect the radiative balance of planet Earth (e.g., Ramanathan et al., 2001): directly by absorbing and scattering the sunlight (e.g., Schwartz, 1996) and indirectly through modifying the microphysical properties of the clouds (e.g., Lohmann and Feichter, 2005). The current state of the scientific knowledge of the total (direct and indirect) aerosol effect is still considered low due to the complexity of these effects (IPCC, 2014).

The refractive index (RI) of the atmospheric aerosols is a key parameter calculating their absorption and scattering and therefore essential for the global modeling of the aerosol's radiative effects. Valenzuela et al. (2018) showed that there is still clearly a need for additional and accurate measurements of the RI. There are more existing optical software packages for the optical properties of the atmospheric particulate matter and these packages extensively use RI values of the different kinds of aerosols. The OPAC (Optical Properties of Aerosols and Clouds; Hess et al., 1998) package is based on laboratory measurements, whereas the HITRAN-RI (HIgh-resolution TRANsmission Refractive Indices; Massie and Hervig, 2013) package uses both laboratory and field measurements for the different included components and allows comparisons between the products using the different RIs as well.

A common method to determine the RI of aerosol particles is an indirect method: the measurement of the absorption and/or scattering of the particles along with the knowledge of the particle's size. The absorption and the scattering of a single particle are determined by the particle's size, shape, and RI. It is most often assumed that particles are spherical and for the theoretical calculations the Mie theory can be used.

Wex et al. (2009) determined the RI of secondary organic aerosol by selecting the particle size using a differential mobility analyzer (DMA) and measuring the scattering signal using an optical particle counter (OPC). The same method was used by Hand and Kreidenweis (2002) on ambient aerosol. Additionally they combined the measurements from an aerodynamic particle sizer as well, in order to gain information on the particles' density. Bukowiecki et al. (2011), Zhang et al. (2013), and Zieger et al. (2015) used the number size distribution with parallel nephelometer and aethalometer measurements to determine the RI of ambient aerosols. A very similar method was used by Virkkula et al. (2006) for the Antarctic site Aboa, assuming that here the imaginary part of the RI can be neglected.

Barkey et al. (2007) measured laboratory-generated particles' number size distribution and light scattering by a polar nephelometer. They introduced an inversion algorithm to obtain the RI. A new and more exotic method is to use optical trapping combined with Mie spectroscopy to capture the RI of atmospheric aerosol samples in the 460-700 nm wavelength range by Shepherd et al. (2018). Cavity ring-down spectroscopy is a method to study the light extinction by aerosol particles. This method was used by Bluvshtein et al. (2012), who introduced a RI retrieval method by measuring the light extinction at two carefully selected size parameters. We have to keep in mind that all abovementioned methods are not direct measurements of the RI. All of these methods search for RI values that provide good agreement in a closure study between different measured quantities.

As we see there are plenty of existing aerosol RI measurements, but the majority of these measurements are based on laboratory-generated particles and only a few on ambient aerosols. And if we look for RI measurements from Antarctica we can only find very few available data. Hogan et al. (1979) collected aerosol particles at the South Pole in a size range between 0.3 and $12 \mu \mathrm{m}$ during a $4 \mathrm{~d}$ period and put oils with known different RIs on them until they could not see the particles in the microscope (i.e., until the applied oil's RI matched the RI of the collected particles). They have found a RI of 1.54 for these samples. Virkkula et al. (2006) derived the RI (assuming a zero imaginary part) of the ambient aerosol at coastal Antarctica during a $12 \mathrm{~d}$ summer campaign and obtained values around 1.43-1.44. Insoluble organic aerosol collected at the Clean Air Sector Laboratory of the British Antarctic Survey station Halley was analyzed by Shepherd et al. (2018). They obtained a RI of 1.47 for samples collected on 60 consecutive days during austral summer 2015.

In this paper we would like to present continuous data on the real RI at the $633 \mathrm{~nm}$ wavelength of the dry ambient aerosol as derived from measurements of an optical particle counter and a scanning mobility particle sizer. To our knowledge this is the first time that such long-term RI measurements of almost 1 year from Antarctica are presented. With this, our study aims at better understanding of the aerosol optical properties at a place where only very few such data are available with special focus on their temporal variability. Given the distinct seasonality of the aerosol composition (see Weller et al., 2008, Figs. 4 and 5 therein), we may likewise expect a seasonality of RI. To this end, continuous yearround data of RI are necessary, in particular regarding the lack of such measurements for the Antarctic realm.

\section{Method}

\subsection{Sampling site}

The measurements presented in this paper were performed in the Air Chemistry Observatory (SPUSO from "Spurenstoffobservatorium") of the German Antarctic station of Neumayer III between February 2017 and January 2018. The SPUSO is situated at the coast of Antarctica on the Ekström shelf ice close to Atka Bay. This observatory is a global site of the WHO's Global Atmosphere Watch program (World Meteorological Organisation, 2016). A detailed description of the site and of the prevailing meteorological conditions has 
already been presented elsewhere (Wagenbach et al., 1988; Weller et al., 2008); here we only give a brief introduction to it.

The SPUSO lies $1.5 \mathrm{~km}$ south of the Neumayer III station and was built on the shelf ice, which moves approximately $120 \mathrm{~m}$ every year to the north. The edge of the shelf ice and thus the sea are $7-21 \mathrm{~km}$ to the north. Due to the remoteness of the measurement site, anthropogenic pollution can barely reach it and the main aerosol source is the Southern Ocean. During the austral summer the sea next to the shelf ice edge and in the nearby Atka bay is ice free, whereas during the long Antarctic winter the next open water can be as far as $100 \mathrm{~km}$ away. Towards the inside of the continent, apart from some remote nunataks there is no ice-free surface.

The only possible contamination source is the Neumayer station itself, where most of the energy is provided by diesel engines. This is the reason why the SPUSO was built $1.5 \mathrm{~km}$ to the south of the station in a clean air sector, and its power supply is provided through a cable from the main station. At this measurement site, northerly winds are almost never present and therefore most of the time we can have a contamination-free sampling. The Neumayer station is completely isolated and not accessible during the winter season, which lasts 9 months.

\subsection{Experimental setup}

The aerosol is continuously sampled through our inlet system, which has its air intake approximately $8 \mathrm{~m}$ above the snow surface. The inlet has an aerodynamic cutoff diameter of $7-10 \mu \mathrm{m}$ at wind speeds of $4-10 \mathrm{~m} \mathrm{~s}^{-1}$ (Weller et al., 2008). Due to the heated measurement container and the low ambient temperatures, aerosol entering the measurement container is dry (relative humidity, $\mathrm{RH} \ll 30 \%$, most of the time even $\mathrm{RH}<10 \%$ ) without any additional drying. The inlet system is made of electropolished stainless steel, and the individual instruments are connected to the inlet via stainless steel or/and conductive silicon tubing. The meteorological data used in this study (temperature, wind direction and speed, and ambient $\mathrm{RH}$ ) were measured directly on the roof of SPUSO.

The particle number size distribution was measured with two commercial instruments: a scanning mobility particle sizer (SMPS) consisting of an electrostatic classifier (TSI 3080) and a condensational particle counter (CPC, TSI 3776) measured in the $16-960 \mathrm{~nm}$ particle mobility diameter range. The SMPS was operated with $2.2 \mathrm{~L} \mathrm{~min}^{-1}$ sheath flow and $0.3 \mathrm{~L} \mathrm{~min}^{-1}$ sample flow. The other instrument was a laser aerosol spectrometer (LAS, TSI 3340), which detects and sizes the particles by measuring the intensity of their scattered light as they pass by the $633 \mathrm{~nm}$ helium-neon active cavity laser. The optical design and the high laser intensity enable the detection of single particles down to $90 \mathrm{~nm}$ diameter. The sample flow of the LAS was set to $0.05 \mathrm{~L} \mathrm{~min}^{-1}$, and the sheath flow was $0.65 \mathrm{~L} \mathrm{~min}^{-1}$. The instrument mea- sured in the size range of $90-5000 \mathrm{~nm}$ and was factory calibrated by polystyrene latex (PSL) particles. Both the SMPS and LAS measured with a 10 min time resolution; however the LAS and the SMPS detect different particles at a time. The LAS counts all the particles which pass the laser beam, whereas the SMPS performed two scans within the $10 \mathrm{~min}$ time period and is only able to detect one particle size at a time, dependent on the voltage that is currently set in the instrument. Therefore if the aerosol changes significantly within $10 \mathrm{~min}$, differences can exist between the measurements of the two instruments as well.

The particle number concentration was measured by a commercial CPC (CPC, TSI 3775) with a 1 min time resolution. A multi-angle absorption photometer (MAAP, Thermo Scientific TM model 5012) operating at a wavelength of $637 \mathrm{~nm}$ (Petzold and Schönlinner, 2004) was used to measure the aerosol absorption during the measurement campaign. The absorption values were converted into equivalent black carbon (eBC; Petzold et al., 2013) mass concentration using a mass absorption efficiency of $6.6 \mathrm{~m}^{2} \mathrm{~g}^{-1}$ and were registered also once per minute. The ionic composition of the aerosol was measured by a low-volume Teflon-nylon filter system, and the filters are analyzed by ion chromatography. The filters were changed daily but not every day at the same time, and therefore the time resolution of the ionic composition varies with time. The average sampling flow was $\approx 3.5 \mathrm{~m}^{3} \mathrm{~h}^{-1}$, and the sampled air volume varied between 30 and $125 \mathrm{~m}^{3}$ in 2017 . The filter sampling is automatically switched off in case of a possible contamination (snow drift, northerly wind direction, wind velocities below 2 or above $20 \mathrm{~m} \mathrm{~s}^{-1}$, and exceedingly high particle number concentrations); see details in Weller et al. (2008). In this study we used the following main ionic species: $\mathrm{NH}_{4}^{+}$, $\mathrm{Na}^{+}, \mathrm{NO}_{3}^{-}$, non-sea-salt (nss) $\mathrm{SO}_{4}^{2-}$, and $\mathrm{MSA}^{-}$(methanesulfonate). The CPC and the MAAP are part of the continuous measurement program of GAW.

\subsection{Correction of the LAS losses}

We have collected data from both the LAS and SMPS instruments for almost 1 year (9 February 2017-20 January 2018). Unfortunately, during most of this time, the LAS was positioned horizontally too far away (ca. $3 \mathrm{~m}$ ) from the inlet such that a significant number of particles were lost in the connecting tube. This problem was first discovered in November 2017. Right after, on 23 November 2017, the instrument was repositioned right below the inlet in order to minimize the particle losses. For this study, we were particularly interested in the particle diameter range between 120 and $340 \mathrm{~nm}$ because we used the number size distribution data in this diameter range for the RI determination (see Sect. 2.6). Therefore, it was important to check whether or not we are able to correct for the particle losses before November 2017 in this diameter range. 


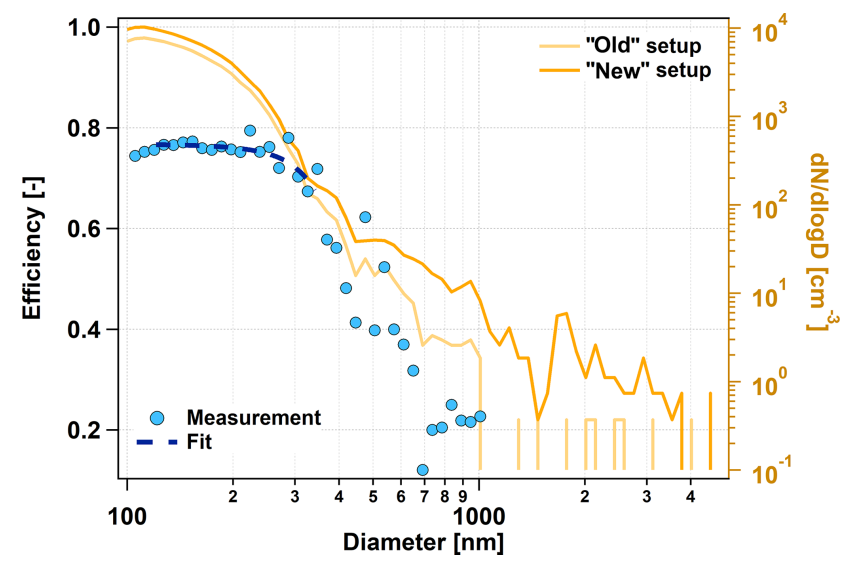

Figure 1. The quantification of the LAS losses in the sampling line. The two orange lines refer to the right axis and show the average room air number size distributions. "Old" setup: time average with the long horizontal tube; "new" setup: time average without the horizontal tube. The blue dots show the particle transmission efficiency through the tube, and the dashed dark blue line shows a polynomial fit in the diameter range which was used for the RI calculation.

Measuring the losses in the sampling line which was used before November 2017 ("old" setup) was a challenging task. At our measurement site, no particle generator was available to perform tests with, and due to the location and isolation of the station, it was also impossible to receive any equipment for the test. Our best option was to use the room air of the measurement container to quantify the particle losses. The room air aerosol was measured by disconnecting the tubing from the inlet and sucking air from inside the measurement container. The room air provided only a low concentration, so that several hours of measurement were needed. One measurement cycle included the number size distribution measurement of the LAS of the room air aerosol in the old setup and right after removing the horizontal tube in the "new" setup with the shorter, vertical tube. To make sure that the aerosol source is stable enough during one cycle, the number size distribution measurement time was reduced to two times of $60 \mathrm{~s}$ with some seconds in between to change between the setups.

All measured number size distributions were averaged separately for the old and the new setups, and the average number size distributions were compared. Figure 1 shows the results of this comparison. If one looks at them (Fig. 1, orange lines, right axis) or at the particle transmission efficiency (the ratio between the two size distributions, Fig. 1 blue dots, left axis) it is obvious that the losses in the old sampling line are significant. Almost all particles with diameters above $1 \mu \mathrm{m}$ were lost, and therefore it is impossible to make any correction there. For this reason, the number size distribution up to $5 \mu \mathrm{m}$ is only available after November 2017. In the diameter range of the RI determination of $120-340 \mathrm{~nm}$, the efficiency is between 0.77 and 0.67 . The losses are signif- icant here as well, but we still consider this to be correctable. To have a continuous correction factor, the transmission efficiency (Fig. 1, blue dots) was fit within the diameter range of interest with a polynomial line. The blue dashed line shows the polynomial fit that was used for the correction.

\subsection{Time averaging}

Due to the low aerosol number concentration in Antarctica, we performed a base time averaging of $1 \mathrm{~h}$ of all measured data. This $1 \mathrm{~h}$ averaging still often resulted in too noisy number size distributions, such that a RI fit was impossible. The particle number concentration at our measurement site has a strong seasonal variability with much lower concentrations in winter than in summer. This strong seasonal variability is the reason why in summer a much shorter time averaging period is sufficient to enable a successful RI fit. To keep the highest possible time resolution of the derived RI, we have chosen the length of the time averaging to be time dependent. And this length was determined by the actual particle concentration.

After performing many tests, we found that the $1 \mathrm{~h}$ averaged SMPS number size distributions, recorded during a time period with an average number concentration of at least $400 \mathrm{~cm}^{-3}$, showed an adequate signal-to-noise ratio for the RI calculation and no further averaging was needed. For all other cases with lower concentrations the hourly averaged data were further averaged until the number of particles detected by the SMPS equaled or exceeded the particle number, which is detected during a $1 \mathrm{~h}$ SMPS scan at $400 \mathrm{~cm}^{-3}$ particle concentration. In some extreme cases in winter, the measured data had to be averaged for $15 \mathrm{~h}$, whereas in summer most of the time the original $1 \mathrm{~h}$ or sometimes $2 \mathrm{~h}$ averaging time was needed. Due to this averaging method we have the highest possible time resolution though not constant, but changing with time, depending on the total particle number concentration. This changing time resolution had to be taken into account for all further time-average or statistical calculations.

\subsection{Recalculation of the LAS number size distribution}

The LAS is factory calibrated using PSL particles having a RI of 1.588 (Eidhammer et al., 2008). In order to be able to recalculate the particle number size distribution for any other RI, we need to calculate the theoretical instrument response (TIR, the signal which the instrument measures) of the LAS

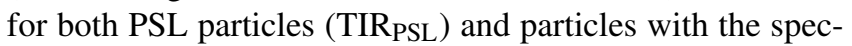
ified RI (TIR $\mathrm{RI}$ ) as a function of the particle diameter. This was done by a custom-written Mie code using the LAS wavelength of $\lambda=633 \mathrm{~nm}$ and a detection angle $\Theta$ between 22 and $158^{\circ}$ with a geometry of a round detector shape.

The LAS delivers the number size distribution $(n(D))$ as the particle number concentration $(N(D))$ sorted into diameter bins: $n\left(D_{i}\right)=\frac{\mathrm{d} N\left(D_{i}\right)}{\mathrm{d} \log \left(D_{i}\right)}$, where $i$ denotes the $i$ diameter 


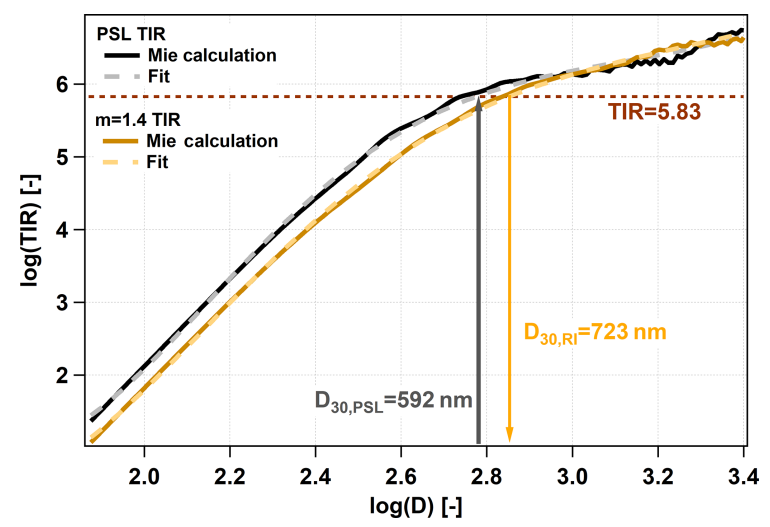

Figure 2. LAS theoretical instrument responses for $m=1.588+0 i$ (black) and $1.40+0 i$ (orange) as a function of the particle diameter. Here we show an example of how an original LAS diameter bin border $\left(D_{30, \mathrm{PSL}}\right)$ was recalculated to the target RI $\left(D_{30, \mathrm{RI}}\right)$.

bin. These bins cover the whole measurement range of the instrument leaving no gaps. Each diameter bin has a lower and a higher boundary $\left(D_{i, \text { lower }}, D_{i, \text { higher }}\right)$. These bin boundaries correspond to the PSL calibration of the LAS. In order to recalculate the number size distribution to another RI, all bin boundary diameters have to be recalculated. This recalculation can be done by using the previously calculated TIR values. (1) For a single PSL calibration-based bin diameter $\left(D_{i, \mathrm{PSL}}\right)$ the instrument response $\operatorname{TIRSLL}_{\mathrm{PSL}}\left(D_{i, \mathrm{PSL}}\right)$ is looked up. (2) Now we look at the TIR values that are calculated using the desired RI. We search for the diameter $\left(D_{i, \mathrm{RI}}\right)$ at which we get the same instrument response as for PSL: $\operatorname{TIR}_{\mathrm{RI}}\left(D_{i, \mathrm{RI}}\right)=\operatorname{TIR}_{\mathrm{PSL}}\left(D_{i, \mathrm{PSL}}\right)$, and that diameter is the recalculated bin boundary diameter. We repeat this for every diameter bin.

The diameter recalculation is not always straightforward because OPCs using a monochromatic laser often suffer from a non-monotonic instrument response at higher diameters (e.g., Hodkinson and Greenfield, 1965; Barnard and Harrison, 1988). This problem of non-monotonic instrument response was solved by smoothing the calculated instrumental response function by fitting a 5th-grade polynomial to

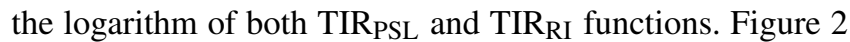
shows an example of how a single bin boundary diameter ( $D_{30 \text {,PSL }}$, the 30th diameter bin border) is recalculated using another RI $(m=1.4+0 i)$. The Mie calculation (solid line) and the polynomial fit (dashed line) are shown for both RIs. The 30th diameter bin border is $592 \mathrm{~nm}$ in our setup, using the original PSL calibration. One can read from Fig. 2 that a PSL particle of this size detected by the LAS results in the same TIR as a particle with the RI of 1.4 and the size of $D_{30, \mathrm{RI}}=723 \mathrm{~nm}$. The same procedure has to be used for every bin boundary diameter and every desired index of refraction. After having the recalculated diameter borders, we can recalculate the number size distribution as well. If the original number size distribution is

$n_{\mathrm{PSL}}\left(D_{\mathrm{PSL}}\right)=\frac{\mathrm{d} N\left(D_{\mathrm{PSL}}\right)}{\mathrm{d} \log \left(D_{\mathrm{PSL}}\right)}$,

then the recalculated number size distribution looks like this:

$n_{\mathrm{RI}}\left(D_{\mathrm{RI}}\right)=\frac{\mathrm{d} N\left(D_{\mathrm{RI}}\right)}{\mathrm{d} \log \left(D_{\mathrm{RI}}\right)}=\frac{\mathrm{d} N\left(D_{\mathrm{RI}}\right)}{\log \left(D_{\mathrm{high}, \mathrm{RI}}\right)-\log \left(D_{\mathrm{low}, \mathrm{RI}}\right)}$,

where $D_{\text {high,RI }}$ is the upper boundary and $D_{\text {low,RI }}$ is the lower boundary of the recalculated diameter bin.

\subsection{Calculation of the effective refractive index}

In order to find the aerosol refractive index, the SMPS and the LAS data in the overlapping size range have to be matched. This matching was done by recalculating the LAS number size distribution using a set of different RIs and finding the one which matches the SMPS number size distribution best at the overlapping size range. The following expression was used after Khlystov et al. (2004) to quantize the difference between the LAS and the SMPS distribution:

$$
\begin{aligned}
\chi(m) & =\frac{1}{N} \cdot \sum_{i=N_{\min }}^{N_{\max }}\left[\log \left(n_{\mathrm{SMPS}}\left(D_{i}\right)\right)\right. \\
& \left.-\log \left(n_{\mathrm{LAS}}\left(m, D_{i}\right)\right)\right]^{2}
\end{aligned}
$$

The SMPS and the LAS have an overlapping size range between 90 and $950 \mathrm{~nm}$; however only the range between 120 and $340 \mathrm{~nm}$ was used for the fit. The SMPS number size distribution was too noisy above $340 \mathrm{~nm}$, and at the lowest diameters the LAS does not have a detection efficiency of unity. The range of the RI was chosen to be 1.3-1.8 with 0.01 steps in between. The imaginary part of the RI was kept at 0 , which is an acceptable assumption considering that the absorption is very low compared to the scattering at our measurement site, with an average single-scattering albedo of 0.992 (Weller et al., 2013). The $\chi(m)$ function was determined for every single $m$ value, and the minimum of this function was searched. That $m$ where $\chi$ reaches its minimum is the $m$ value we look for and we interpret as the RI of the measured aerosol. Those cases were omitted where the $\chi$ function did not have an explicit minimum or exceeded a limit. After manual inspection of many fit procedures this limit was set to the value of 0.02 . Such cases might occur if too much noise is present in the data or if the size distribution was varying too much during the time period of one scan. Next to this numerical criterion every single scan was manually checked as well.

The RI derived with our method is representative for the particle diameter range of $120-340 \mathrm{~nm}$, which was used for 


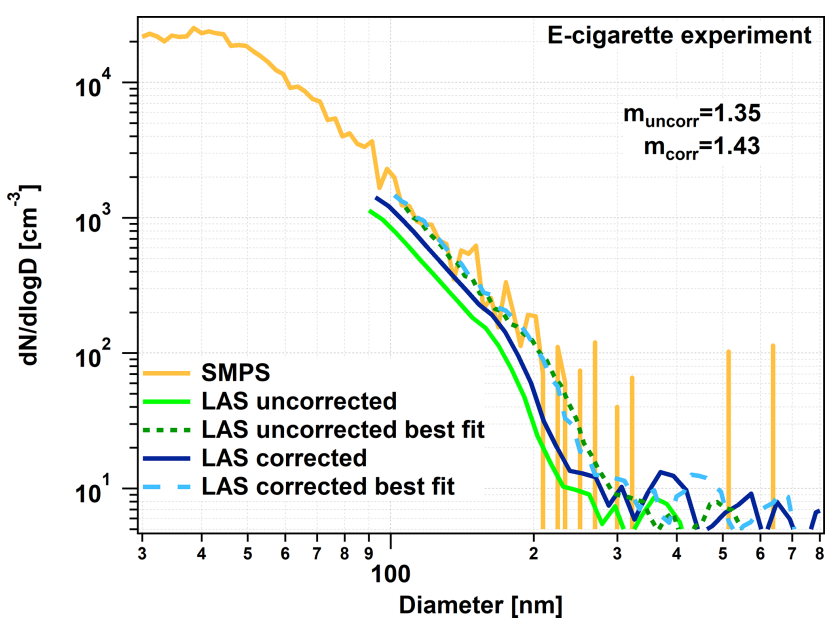

Figure 3. The e-cigarette experiment, showing the validation of our LAS correction. The orange line shows the measured SMPS number size distribution, the green lines the uncorrected LAS number size distribution (light: original; dark and dashed: best fit with $m_{\text {uncorr }}$ calculated RI), and the blue lines (dark: original; light and dashed: best fit with $m_{\text {corr }}$ calculated RI) are the loss-corrected LAS number size distributions.

the RI calculation. If we can assume that all particles in the number size distribution have the same RI, our calculated RI is the true RI. If the chemical composition of the aerosol changes with the particle size, it is possible that the RI is also size dependent. Hence, our derived RI might differ from the average RI, which corresponds to the complete aerosol population. In addition we assumed a spherical shape of the particles and a negligible imaginary part of the RI. Therefore we term our derived RI the effective refractive index ( $\mathrm{RI}_{\mathrm{eff}}$ ) from now on, and for later conclusions we have to keep in mind that the $\left(\mathrm{RI}_{\text {eff }}\right)$ might not be the true $\mathrm{RI}$ of an individual particle.

\section{Results and discussion}

\subsection{Verification of the LAS correction}

In order to verify the used LAS correction (see Sect. 2.3), measurement of particles with known RI and spherical shape was necessary. The lack of any particle generator left us with not many possibilities. A commercial e-cigarette (Joyetech eGo) was available at the station, and we used this to generate particles for testing purposes. E-cigarette liquid contains glycerin, propylene glycol, water, nicotine, and flavorings, and the formed aerosol particles are spherical liquid droplets. Pratte et al. (2016) measured the RI of many e-cigarettes of different types and obtained values between 1.429 and 1.436, and therefore we assume that our generated test particles had a RI of 1.43 .

We filled a plastic bag of $\approx 100 \mathrm{~L}$ volume with particlefree air, and then we added two to three puffs of the e- cigarette smoke using a small, hand-operated air pump. After that, we let the aerosol particles coagulate in the bag for $10-15 \mathrm{~min}$ in order to let the particles reach the detection diameter range of the LAS. The e-cigarette test was performed with the same setup as the old measurement setup using the long vertical tube.

We used the method introduced in Sect. 2.5 and 2.6 to calculate the RI of this e-cigarette smoke, first with the uncorrected LAS data and then applying the above-introduced (Sect. 2.3) LAS correction. These values can be compared to the e-cigarette smoke's literature RI value of 1.43 to check whether the LAS correction works well or not. For this fit we have chosen a slightly different particle size range of 110 $220 \mathrm{~nm}$ because the form of the number size distribution was different from the ambient one.

Figure 3 shows the results of the e-cigarette experiment. Without using the LAS correction on the LAS data (green lines) we get a RI of 1.35 from the best fit. This value is significantly lower than the literature RI value of 1.43 , suggesting that the LAS losses had a high influence on the retrieved RI and that a correction is necessary. Using the loss-corrected LAS size distribution, the best fit between the SMPS and the LAS data (blue lines) resulted in the RI of 1.43 , which agrees with the literature value. This verifies our LAS correction, and we applied it to all LAS data before November 2017.

\subsection{Sensitivity of the RI calculation to the number size distribution measurement}

The accuracy of our $\mathrm{RI}_{\text {eff }}$ calculation mainly depends on the measured input data's uncertainty, which is the uncertainty of the number size distribution measurements in our case. Here, we discuss the sensitivity of the derived $\mathrm{RI}_{\mathrm{eff}}$ values introduced by the measurement uncertainty. An intercomparison between many mobility particle size spectrometers showed that all of the different investigated instruments measured within an uncertainty range of $\pm 10 \%$ (Wiedensohler et al., 2012). We use this value for our SMPS, and we assume that the LAS has the same uncertainty as well.

In order to investigate the effect of this measurement uncertainty we take the worst-case scenarios, by either adding $10 \%$ to the particle number concentration measured by the SMPS and subtracting $10 \%$ from the LAS or the other way around. We calculated, for a 1-month measurement period, the $\mathrm{RI}_{\text {eff }}$ values using these modified number size distributions next to the original ones. Choosing a $10 \%$ higher SMPS concentration and $10 \%$ lower LAS concentration resulted in lower calculated $\mathrm{RI}_{\text {eff. }}$ On average the values were 0.045 lower compared to the original values, which translates into an average $3.1 \%$ error. The other scenario results in artificially high values, which turned out to be on average 0.050 and this means an error of $3.5 \%$. This shows that even assuming the worst-case scenario would cause an acceptable error, and most probably we can expect a lower uncertainty in reality. 

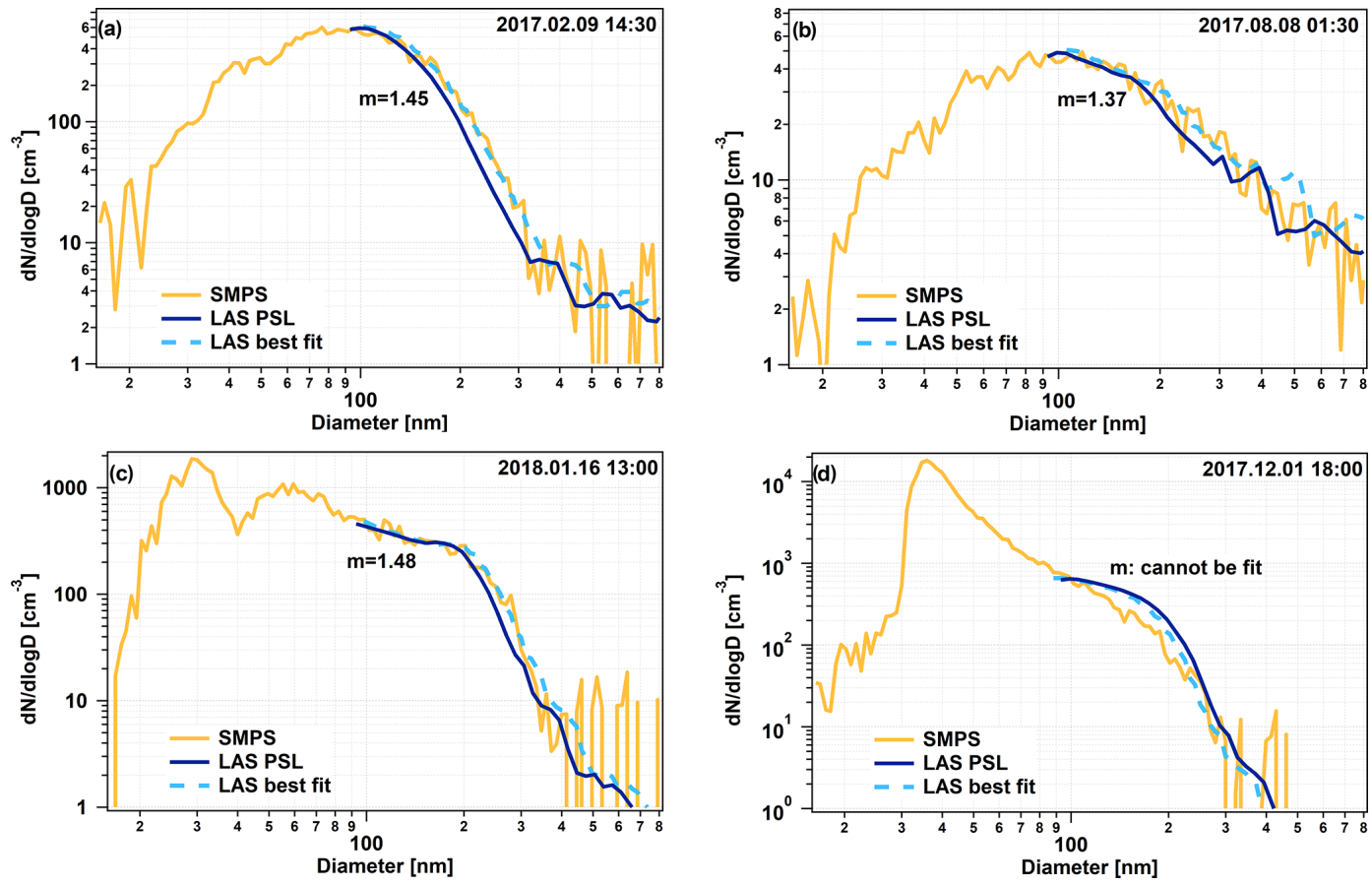

Figure 4. Four examples of the refractive index fit performance. The orange line shows the measured SMPS number size distribution, whereas the blue lines (dark: PSL calibrated; light and dashed: best fit) show the LAS number size distributions.

\subsection{RI calculation examples}

Figure 4 shows four examples of the RI fitting procedure's performance in different cases. The first example (Fig. 4a) is from the summer season when the number concentration was high enough that a $1 \mathrm{~h}$ averaging period was reasonable. The orange line shows the measured SMPS scan, whereas the dark blue line shows the simultaneously measured LAS number size distribution with the factory calibration. The dark blue line lies below the SMPS line, which indicates that the built-in calibration RI of 1.588 overestimates the prevailing RI. The fitting procedure verifies this and the best fit belongs to the recalculated LAS scan with the RI of 1.45 , which we consider to be the effective refractive index, $\mathrm{RI}_{\mathrm{eff}}$, of the dry aerosol at that time.

Figure $4 \mathrm{~b}$ shows a similar situation from winter with much lower particle concentrations and therefore a longer averaging time of $11 \mathrm{~h}$. The obtained RI was quite low: 1.37 in this case. An uncommon example can be seen in Fig. $4 \mathrm{c}$ when the number size distribution was trimodal. The fit was successful again; the retrieved RI is 1.48. As the last example (Fig. 4d), we show a case where the fit was unsuccessful, and we could not retrieve a valid RI. The fitting procedure returned a best fit, but the value of $\chi$ exceeded 0.02 , and it is also clearly visible that this best solution does not fit the measured SMPS number size distribution very well. The reason why the fit did not work in this case was that the aerosol population was significantly changing within the duration of the SMPS scan. During the first half of the scan an aerosol plume with very high concentration reached the instruments. This appears in the SMPS scan as a very high fraction of small particles because the SMPS selected and measured the smaller particles during the first half of the scan. Conversely, the LAS captures all particles with different diameters at the same time, and therefore this event appears as an elevated overall concentration. This was an extreme and exceptional situation where some unavoidable construction work was carried out around the SPUSO using machines powered by diesel engines.

\subsection{Seasonal variability and mean value of the refractive index}

We have collected data during almost a complete year (from 9 February 2017 to 20 January 2018), giving us the unique possibility of calculating the long-term $\mathrm{RI}_{\mathrm{eff}}$ and analyzing its seasonal variability. Figure 5 shows this seasonal variability, where some statistical values of the monthly $\mathrm{RI}_{\mathrm{eff}}$ are presented. The gray circles show the monthly mean values with the standard deviation (SD) as error bars, the black bars the medians, and the gray bars the 25th and 75th percentiles. The orange bar chart belongs to the right axis and indicates

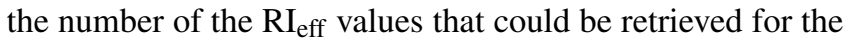
corresponding month. The same data are also shown in Table 1 complemented by the yearly mean values.

The mean $\mathrm{RI}_{\text {eff }}$ during our complete measurement period was 1.44 with a comparable median of 1.41 . As already mentioned, there are only very few other RI measurements from Antarctica. Virkkula et al. (2006) calculated the RI values 


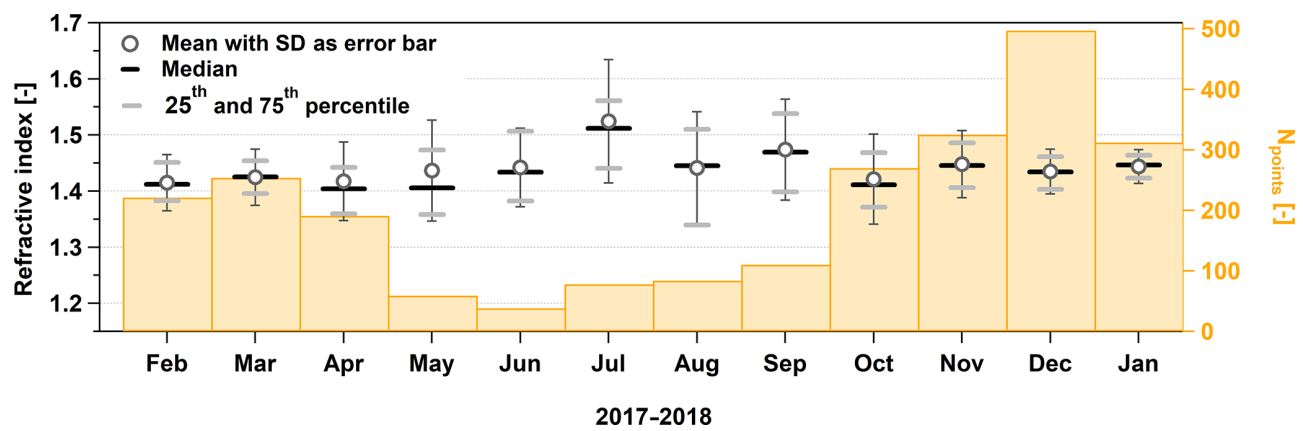

Figure 5. The monthly averages (with error bars as the standard deviation), medians, and percentiles of $\mathrm{RI}_{\mathrm{eff}}$ from coastal Antarctica, measured at $\lambda=633 \mathrm{~nm}$ for dry aerosol particles. The orange bars refer to the right axis and show the number of successful RI retrievals in the corresponding month.

Table 1. The monthly and yearly $\left(\sum\right.$ ) averages, standard deviations (SD), medians, and percentiles of the RI $\mathrm{I}_{\mathrm{eff}}$ from coastal Antarctica, measured at $\lambda=633 \mathrm{~nm}$ for dry aerosol particles.

\begin{tabular}{lrrrrrr}
\hline Month & $\begin{array}{r}\text { 25th } \\
\text { percentile }\end{array}$ & Median & $\begin{array}{r}\text { 75th } \\
\text { percentile }\end{array}$ & Mean & SD & $N_{\text {points }}$ \\
\hline Feb & 1.38 & 1.41 & 1.45 & 1.41 & 0.05 & 221 \\
Mar & 1.40 & 1.43 & 1.45 & 1.42 & 0.05 & 254 \\
Apr & 1.36 & 1.40 & 1.44 & 1.41 & 0.07 & 191 \\
May & 1.36 & 1.40 & 1.47 & 1.42 & 0.09 & 59 \\
Jun & 1.38 & 1.43 & 1.51 & 1.44 & 0.07 & 38 \\
Jul & 1.44 & 1.51 & 1.56 & 1.50 & 0.11 & 78 \\
Aug & 1.34 & 1.45 & 1.51 & 1.44 & 0.10 & 84 \\
Sep & 1.40 & 1.47 & 1.54 & 1.47 & 0.09 & 110 \\
Oct & 1.37 & 1.41 & 1.47 & 1.42 & 0.08 & 270 \\
Nov & 1.41 & 1.45 & 1.49 & 1.45 & 0.06 & 325 \\
Dec & 1.40 & 1.43 & 1.46 & 1.44 & 0.04 & 497 \\
Jan & 1.42 & 1.45 & 1.46 & 1.44 & 0.03 & 312 \\
\hline$\sum$ & 1.37 & 1.41 & 1.46 & 1.44 & 0.08 & 2439 \\
\hline
\end{tabular}

from number size distribution and scattering coefficient measurements at the Finnish Antarctic summer station Aboa. Aboa is situated approximately $300 \mathrm{~km}$ to the west of the Neumayer station and lies a little further away from the sea. These measurements were performed in the summer of 2000 during a $12 \mathrm{~d}$ period. They found a mean RI of 1.454 at $\lambda=550 \mathrm{~nm}$ and 1.460 at $\lambda=700 \mathrm{~nm}$ excluding a nucleation event where unrealistically low values (lower than the RI of water) were derived. Our average RI values have a very good agreement with their average RI values, and this agreement is even better considering only our mean $\mathrm{RI}_{\mathrm{eff}}$ value from January (1.45).

Concerning the monthly averages, it is interesting that in spite of the existing strong seasonal variability of both the aerosol concentration (Jaenicke et al., 1992; Weller et al., 2011) and chemical composition (Wagenbach et al., 1988) the RI does not or only slightly shows a comparable behavior: the monthly averages of $\mathrm{RI}_{\text {eff }}$ remain quite constant and remain within the range of 1.40-1.50. There are two winter months with higher RIs: July with a mean of 1.50 and
September with 1.47 . These values are significantly different from the yearly mean (determined by using a statistical $t$ test with a significance level of 0.01). In both cases we have only relatively few data points due to extremely low particle concentrations and therefore we can only speculate on the reason for the slightly higher values. In winter the fraction of sea salt is higher than in summer and sea salt has a slightly higher RI than the other salts present in the aerosol phase (see Sect. 3.5).

The monthly $\mathrm{RI}_{\text {eff }}$ distributions are quite narrow. However, due to the necessary long averaging time between 1 and $20 \mathrm{~h}$, a potentially higher short-term variability may not be represented. Although the $\mathrm{SD}$ of $\mathrm{RI}_{\mathrm{eff}}$ comprising the whole measurement period is 0.08 , we observed a statistically significant seasonality in the monthly data. The winter months (June to September) seem to have a higher scatter (Fig. 5 gray bars) and higher SD values (0.11 in July vs. 0.03 in January, Fig. 5 error bars). We found a similar tendency in the chemical composition with higher variability during the austral winter compared to summer. This might be one reason 
for the higher scatter in the $\mathrm{RI}_{\text {eff }}$ values, apart from probably higher uncertainty of the fitting method due to extremely low wintertime particle number concentrations.

\subsection{Link to the chemical composition}

The aerosol chemical composition shows a strong seasonal variation at our measurement site. The dominant aerosol component is sea salt with around $50 \%$ of the total mass in summer and $86 \%$ in winter (Weller et al., 2008). While negligible during winter, biogenic sulfur aerosol reaches its annual maximum in austral summer between January and March (Minikin et al., 1998). At our investigated wavelength of $633 \mathrm{~nm}$, sea salt has a RI of 1.49 (Shettle and Fenn, 1979), sulfuric acid 1.42 (Palmer and Williams, 1975), ammonium sulfate 1.53 (Toon et al., 1976), ammonium bisulfate 1.47 (Chylek and Wong, 1995), sodium nitrate 1.46 (Cotterell et al., 2017), ammonium nitrate 1.52 (Toon et al., 1976), MSA 1.43 (Virkkula et al., 2006), and black carbon $1.75+0.43 i$ (Hess et al., 1998).

The chemical composition was determined from the daily filter measurements of the ionic composition and from the $\mathrm{eBC}$ measurement of the MAAP. The mass concentration of the dominant component of sea salt was calculated from the $\mathrm{Na}^{+}$ion. It was assumed that $\mathrm{NH}_{4}^{+}$is preferentially present as ammonium sulfate $\left(\left(\mathrm{NH}_{4}\right)_{2} \mathrm{SO}_{4}\right)$ and/or ammonium bisulfate $\left(\mathrm{NH}_{4} \mathrm{HSO}_{4}\right)$ salt due to the high nss-SO $\mathrm{SO}_{4}^{2-} / \mathrm{NH}_{4}^{+}$ratio of around $11.2 \pm 8$ (annual mean $\pm \mathrm{SD}$ ). In addition, formation of ammonium nitrate $\left(\mathrm{NH}_{4} \mathrm{NO}_{3}\right)$ has to be considered. Part of the nitrate can also be bound as $\mathrm{NaNO}_{3}$. The remaining $\mathrm{SO}_{4}^{2-}$ was assumed to be present as sulfuric acid.

We do not have any information on the organic carbon mass fraction for our measurement period, and therefore we could not include this component into the calculation. However, previous water-soluble organic carbon (WSOC) mass concentration measurements (Weller et al., 2015) showed that in the austral summer of 2011 the WSOC average mass fraction was less than $3 \%$ and therefore we believe that organic carbon does not have a significant influence on the resulting RI. Using this chemical composition and assuming that the aerosol is homogeneously and internally mixed, the RI can be calculated from the volume fraction and the RI of the individual components. The imaginary part of the RI was again neglected, which is a justified assumption because the volume fraction of the eBC never exceeded $0.1 \%$ in 2017. This amount of $\mathrm{eBC}$ would add at most $\mathrm{a} \approx 4 \cdot 10^{-3} i$ imaginary value to the RI.

The average RI calculated from the chemical composition in 2017 becomes 1.47 and is in a good agreement with the optically retrieved $\mathrm{RI}_{\text {eff }}$ of 1.44 . The reason for the slight discrepancy might be caused by the used assumptions. In addition and in contrast to the bulk chemical composition, the RI calculation derived from the SMPS and OPC data is based on a limited size range between 120 and $340 \mathrm{~nm}$. As discussed later in Sect. 3.7, RI changes slightly with the particle size.

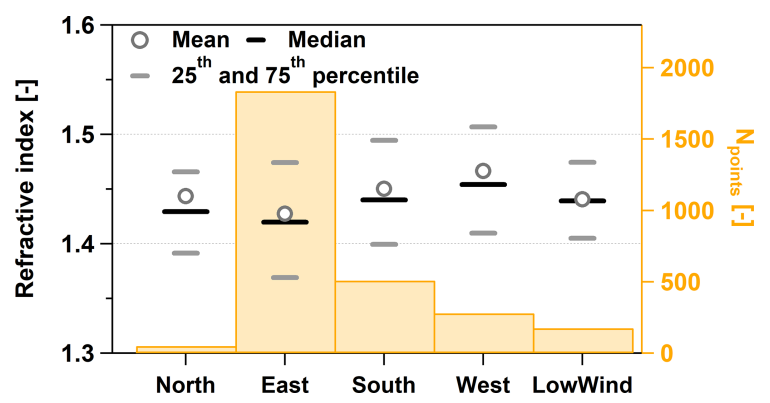

Figure 6. The averages, medians, and percentiles of the $\mathrm{RI}_{\mathrm{eff}}$ from coastal Antarctica separated by the wind direction, measured at $\lambda=$ $633 \mathrm{~nm}$ for dry aerosol particles. The orange bars refer to the right axis and show the number of successful RI retrievals.

Finally, we calculated RI separately for summer (November to February) and winter (March to October) from the aerosol chemical composition. We found higher RI values of 1.48 during austral winter compared to 1.45 during summer. This may be caused by the much higher sea salt aerosol portion during winter with the highest RI among the ionic compounds. Note also the significantly higher $\mathrm{RI}_{\text {eff }}$ values for the winter months July and September (Fig. 5).

\subsection{Impact of general weather situation and local contamination}

Neumayer station is situated $1.5 \mathrm{~km}$ north of the measurement site; thus contamination during northerly winds, but also when the wind speeds are very low, has to be considered. We start with examining whether the actual wind direction influences our data in general, followed by a case study when diesel engines were operated right next to the measurement site. Contamination is mainly associated with high concentrations of black carbon. Black carbon has a RI of $1.75+0.43 i$ (Hess et al., 1998), which is considerably higher than of any other natural chemical components of the aerosol. Note also the distinct imaginary part of the RI.

The prevailing wind direction at the SPUSO is east, associated with high wind speeds above $10 \mathrm{~m} \mathrm{~s}^{-1}$, frequently exceeding even $20 \mathrm{~m} \mathrm{~s}^{-1}$. Easterly wind directions, especially if they are accompanied by high wind speeds, are characteristic for the impact of passing cyclones and marine air entry. The second frequent wind direction is south, with wind speeds generally below $10 \mathrm{~m} \mathrm{~s}^{-1}$. This weather situation is characteristic for advection of more continental air masses by katabatic winds. Westerly winds are usually caused by lowpressure systems in the southern Weddell region and associated with moderate winds speeds between 10 and $20 \mathrm{~m} \mathrm{~s}^{-1}$. Northerly winds are virtually absent (König-Langlo et al., 1998), and if present they mark a period of potential contamination from the station. We have separated the $\mathrm{RI}_{\text {eff }}$ data according to different wind direction sectors to examine whether different air masses are associated with parti- 

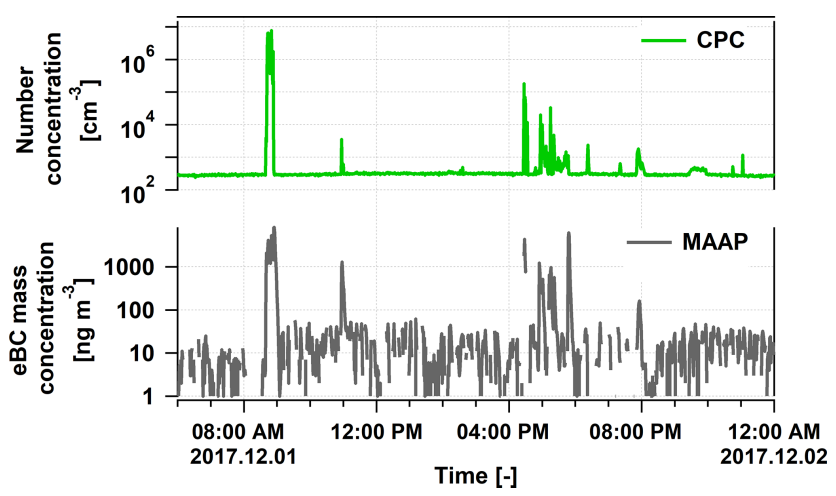

Figure 7. The particle number concentration (green) and the equivalent black carbon mass concentration (black) measured on 1 December 2017.

cles showing different RI values. To this end, we defined the wind direction sector between 315 and $45^{\circ} \mathrm{N}, 45$ and $135^{\circ} \mathrm{E}$, 135 and $225^{\circ} \mathrm{S}$, and 225 and $315^{\circ} \mathrm{W}$. We categorized all data associated with wind speeds below $2 \mathrm{~m} \mathrm{~s}^{-1}$ separately (LowWind in Fig. 6).

Overall, our measurement period was representative and meaningful for each individual sector, even for the inherently few data related to northerly wind directions. Figure 6 shows the $\mathrm{RI}_{\text {eff }}$ values, sorted according to the mentioned categories. The gray circles show the time averages, the black bars the medians, and the gray bars the 25th and 5th percentiles. In summary, no significant dependency of $\mathrm{RI}_{\text {eff }}$ on the wind direction or wind speed is observable. We conclude that the general weather situation, just like local contami-

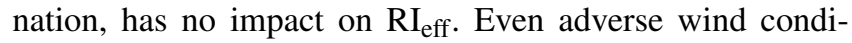
tions associated with potential contamination from the exhaust fumes of the main station did not cause any significant change of $\mathrm{RI}_{\text {eff }}$.

In order to further investigate the problem of the contamination, we performed a case study on a time period when planned contamination reached the SPUSO. This was the same construction event which was already shown in Fig. 4d as an example for an unsuccessful fit when the aerosol was changing too fast. On the day of 1 December 2017, dieselengine-powered machines were in operation in the very close vicinity of the measurement site.

Figure 7 shows the particle number concentration (green) and the black carbon mass concentration (black) as measured by the CPC and MAAP, respectively, during this construction episode. The highest concentrations were present during the morning and the late afternoon even exceeding $6 \cdot 10^{6} \mathrm{~cm}^{-3}$ and $8 \mu \mathrm{g} \mathrm{m}^{-3}$, which are 3-4 orders of magnitude higher than the values without contamination (Weller et al., 2011; Weller et al., 2013). Unfortunately, these concentrations changed very fast, depending on whether the engine emissions were directly reaching our inlet, and therefore most of the time we were not able to perform a fit for the RI. We have only one single scan when the concentration was stable enough and

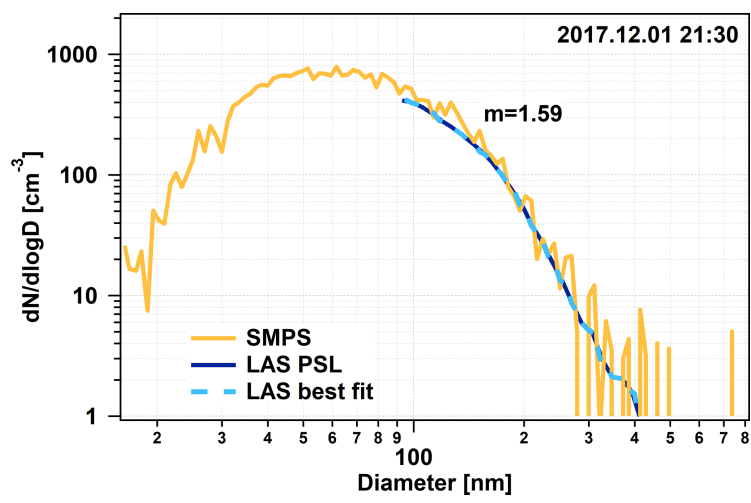

Figure 8. A successful RI fit from 1 December 2017 with high contamination present.

elevated, allowing us to assume that we determined $\mathrm{RI}_{\text {eff }}$ for a contaminated situation.

Figure 8 shows this fit with the retrieved RI of 1.59. One can see that the original LAS scan fits very well already, which means that the RI of the factory calibration of PSLs gives us a good solution. This retrieved $\mathrm{RI}_{\text {eff }}$ is significantly higher than the values we normally got. We can assume that the increased black carbon concentration caused this effect, and increased RI values might be an indicator for strong contamination at this site. This time period, and any other time period with known contamination, was removed from the statistical calculations.

\subsection{Size-dependent contribution to the scattering}

In the following we will calculate the contribution of the particles with different sizes to the scattering coefficient. Unfortunately, the LAS data were not usable above $600 \mathrm{~nm}$ during the time period when the particle losses were high, and therefore we can only perform these calculations for an almost 2-month long summer period (1 December 201720 January 2018) when the LAS was installed right below the aerosol inlet. It was assumed that the derived $\mathrm{RI}_{\text {eff }}$ is valid along the complete number size distribution (between 16 and $5000 \mathrm{~nm}$ ) and that the particles are spherical and thus Mie calculation can be used for the determination of the singleparticle scattering at the wavelength of $633 \mathrm{~nm}$. The scattering coefficient size distribution of the dry aerosol was calculated as follows:

$\frac{\mathrm{d} \sigma_{s}(D)}{\mathrm{d} \log D}=C_{\mathrm{s}}(D, \lambda, m) \cdot \frac{\mathrm{d} N(D)}{\mathrm{d} \log D}$,

where $\sigma_{s}$ is the scattering coefficient in reciprocal meters, $m$ is the derived, time-dependent $\mathrm{RI}_{\text {eff }}$ without a unit, and $C_{\mathrm{S}}$ is the scattering cross section of the individual particles in square meters. To calculate $C_{\mathrm{s}}$ we used our custom-written Mie code. 


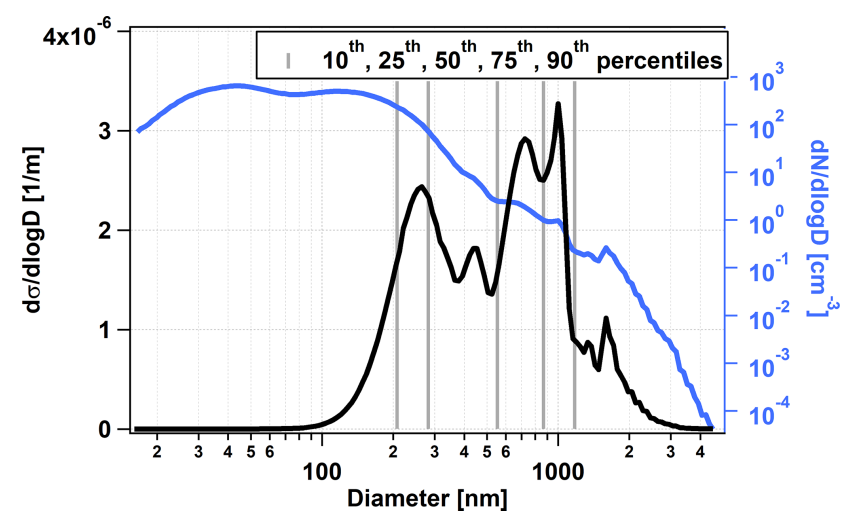

Figure 9. The average dry scattering coefficient size distribution (black line) at the $633 \mathrm{~nm}$ wavelength and the corresponding particle number size distribution (blue line, right axis) as a function of the particle diameter. The gray lines show the 10th, 25th, 50th, 75th, and 90th percentiles of the scattering coefficient distribution.

Figure 9 shows the time average of $\mathrm{d} \sigma_{s}(D) / \mathrm{d} \log D$ as a function of the particle diameter. Next to it, the average number size distribution (blue line, right logarithmic axis) for the same time period is also shown. As we can see, particles smaller than $100 \mathrm{~nm}$ or larger than $3 \mu \mathrm{m}$ do not contribute significantly to the scattering. A total of $80 \%$ of the scattering amount comes from the size range between 208 and $1170 \mathrm{~nm}$. Interestingly, the distribution is multimodal, having two main peaks around 260 and $860 \mathrm{~nm}$. The median of the distribution is at $550 \mathrm{~nm}$, which is much higher than the median of the number size distribution $(64 \mathrm{~nm})$, as expected, because scattering increases faster than linearly as a function of the particle diameter. The average number size distribution is also multimodal with two distinct peaks around $40 \mathrm{~nm}$ and $140 \mathrm{~nm}$. Considering the time evolution and not temporal averages we see, these two peaks, as well as the two main peaks of the scattering coefficient size distribution, are often present simultaneously. In conclusion, the bimodality is not the product of time averaging of single modes appearing at different times.

Finally we investigate the effect of neglecting the imaginary part of the RI for the scattering coefficient. As we have seen in Sect. 3.5 including the eBC in the chemical composition adds at most an imaginary part of $\approx 4 \cdot 10^{-3} i$ to the RI. We recalculated the average scattering coefficient size distribution adding this imaginary part to the RI. This gives us a highest possible estimate on the error we make if we would neglect the imaginary part of RI. It turns out that the relative difference of the scattering coefficient size distribution considering $4 \cdot 10^{-3} i$ RI instead of 0.0 i never exceeds $1.7 \%$ irrespective of the particle diameter.

\subsection{Size dependence of the refractive index}

To examine the dependence of $\mathrm{RI}_{\mathrm{eff}}$ on the given particle size distribution, we again have to restrict the time period

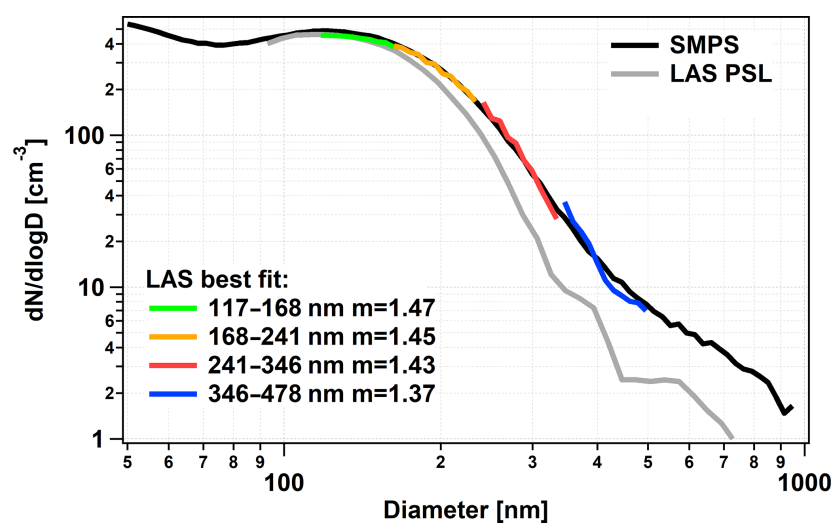

Figure 10. The average dry aerosol number size distribution measurements during December 2017 and January 2018 as measured by the SMPS (black line) and the LAS (gray line). The colored lines show the four individual RI fits using four different particle size ranges.

to 1 December 2017-20 January 2018 when the LAS's particle losses were minimized. During this period we have an SMPS-LAS overlapping size range between 120 and $900 \mathrm{~nm}$. If we calculate the temporal average over this complete time period, most of the noise is averaged out as well, so that we can use most of this overlapping size range for the RI fit. Moreover, the overall size distribution range can now be divided into four subranges suitable for separate $\mathrm{RI}_{\mathrm{eff}}$ calculations, representative for the corresponding subrange (Fig. 10).

Figure 10 shows the time-averaged LAS (gray line) and SMPS (black line) number size distributions. We have chosen the following particle size ranges for the separate RI fit: 117-168, 168-241, 241-346, and 376-478 nm, ensuring that we have a similar number of size distribution measurement points for the fit procedure in each of the size ranges.

With the increasing particle size, we needed to apply a lower RI in order to have the best match between the LAS and the SMPS. In the first range we obtained a $\mathrm{RI}_{\text {eff }}$ of 1.47 , in the second 1.45 , in the third 1.43 , and in the fourth 1.37. According to Fig. 10 the $\mathrm{RI}_{\text {eff }}$ decreases slightly within the first three subranges of particle diameter $\left(\mathrm{RI}_{\text {eff }}\right.$ between 1.47 and 1.43 ), but more pronouncedly for the highest range $\left(\mathrm{RI}_{\mathrm{eff}}=1.37\right)$

The conspicuously lower $\mathrm{RI}_{\text {eff }}$ in the highest investigated size range may originate from a significantly changing chemical composition. Interestingly, sea salt particles should dominate this higher size range, but this would result in a higher

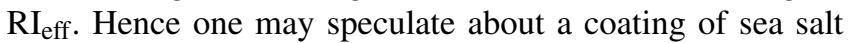
particles in this special case (probably organic material with typically lower RI). The presence of a coating or a different aerosol source might also explain the bimodality of the scattering coefficient size distribution (Sect. 3.7). However, we have to keep in mind that this is pure speculation and we have no proof of it. 


\section{Conclusions}

We have calculated the real RI for dry natural aerosol at a coastal Antarctic measurement site using the overlapping size range of two instruments measuring the number size distribution in two different ways: optically and by electrical mobility. The yearly average ( \pm SD) of the RI was calculated based on the data from almost a complete year and turned out to be $1.44( \pm 0.08)$. This average is in very good agreement with the RI value of 1.47 , which we derived from filter-based chemical composition measurements. The good agreement shows that at least for coastal Antarctica this method reliably delivers the RI values without the additional effort of a chemical characterization of the aerosol.

Based on this, we recommend this single, temporally constant refractive index value for modeling of aerosol optical properties. In this context we suggest supporting investigations to examine the validity of this approach and the usage of season-independent $\mathrm{RI}_{\mathrm{eff}}$ values for the Antarctic region.

In spite of the strong seasonal variability of the chemical composition at the measurement site (e.g., $86 \%$ sea salt present in winter, $50 \%$ in summer), we could not identify a corresponding seasonal trend of the RI, which is in good agreement with RI derived from the chemical composition of the present aerosol. We conclude that the given high variability of the ionic composition of the aerosol typical for coastal Antarctica causes only minor variability in associated RI values. We could not find any significant influence from the wind direction either. We conclude that the general weather situation, just like local contamination, has no significant impact on $\mathrm{RI}_{\text {eff }}$.

In forthcoming related investigations at Neumayer, a yearround optical closure experiment is planned. For this, the size range between $16 \mathrm{~nm}$ and $5 \mu \mathrm{m}$ as well as aerosol scattering coefficients by integrated nephelometer measurements will be employed.

Data availability. Data reported here are available at https://doi.org/10.1594/PANGAEA.899429 (Weller and Jurányi, 2019a) and https://doi.org/10.1594/PANGAEA.899430 (Weller and Jurányi, 2019b) for scientific purposes.

Author contributions. ZJ has performed the measurements, analyzed and interpreted the data, and written the paper. RW built up the measurement site, supervised the measurements and the data analysis, and reviewed and edited the paper.

Competing interests. The authors declare that they have no conflict of interest.

Acknowledgements. The authors would like to thank all members of the 37th overwintering team of the Neumayer III station for their support and for being a great group. The first author of the paper would like to express her gratitude to her brother for his support during the harsh winter months in Antarctica.

Financial support. The article processing charges for this openaccess publication were covered by a Research Centre of the Helmholtz Association.

Review statement. This paper was edited by Paola Formenti and reviewed by three anonymous referees.

\section{References}

Barkey, B., Paulson, S. E., and Chung, A.: Genetic algorithm inversion of dual polarization polar nephelometer data to determine aerosol refractive index, Aerosol Sci. Tech., 41, 751-760, https://doi.org/10.1080/02786820701432640, 2007.

Barnard, J. C. and Harrison, L. C.: Monotonic responses from monochromatic optical particle counters, Appl. Optics, 27, 584592, https://doi.org/10.1364/AO.27.000584, 1988.

Bluvshtein, N., Flores, J. M., Riziq, A. A., and Rudich, Y.: An approach for faster retrieval of aerosols' complex refractive index using cavity ring-down spectroscopy, Aerosol Sci. Tech., 46, 1140-1150, https://doi.org/10.1080/02786826.2012.700141, 2012.

Bukowiecki, N., Zieger, P., Weingartner, E., Jurányi, Z., Gysel, M., Neininger, B., Schneider, B., Hueglin, C., Ulrich, A., Wichser, A., Henne, S., Brunner, D., Kaegi, R., Schwikowski, M., Tobler, L., Wienhold, F. G., Engel, I., Buchmann, B., Peter, T., and Baltensperger, U.: Ground-based and airborne in-situ measurements of the Eyjafjallajökull volcanic aerosol plume in Switzerland in spring 2010, Atmos. Chem. Phys., 11, 10011-10030, https://doi.org/10.5194/acp-11-10011-2011, 2011.

Chylek, P. and Wong, J.: Effect of absorbing aerosols on global radiation budget, Geophys. Res. Lett., 22, 929-931, https://doi.org/10.1029/95GL00800, 1995.

Cotterell, M. I., Willoughby, R. E., Bzdek, B. R., Orr-Ewing, A. J., and Reid, J. P.: A complete parameterisation of the relative humidity and wavelength dependence of the refractive index of hygroscopic inorganic aerosol particles, Atmos. Chem. Phys., 17, 9837-9851, https://doi.org/10.5194/acp-17-9837-2017, 2017.

Eidhammer, T., Montague, D. C., and Deshler, T.: Determination of index of refraction and size of supermicrometer particles from light scattering measurements at two angles, J. Geophys. Res.Atmos., 113, D16206, https://doi.org/10.1029/2007JD009607, 2008.

Hand, J. L. and Kreidenweis, S. M.: A new method for retrieving particle refractive index and effective density from aerosol size distribution data, Aerosol Sci. Tech., 36, 1012-1026, https://doi.org/10.1080/02786820290092276, 2002.

Hess, M., Koepke, P., and Schult, I.: Optical properties of aerosols and clouds: the software package OPAC, B. Am. Meteorol. Soc., 79, 831-844, https://doi.org/10.1175/15200477(1998)079<0831:OPOAAC>2.0.CO;2, 1998. 
Hodkinson, J. R. and Greenfield, J. R.: Response calculations for light-scattering aerosol counters and photometers, Appl. Optics, 4, 1463-1474, https://doi.org/10.1364/AO.4.001463, 1965.

Hogan, A. W., Barnard, S., and Bortiniak, J.: Physical properties of the aerosol at the South Pole, Geophys. Res. Lett., 6, 845-848, https://doi.org/10.1029/GL006i011p00845, 1979.

IPCC: Technical Summary, Cambridge University Press, https://doi.org/10.1017/CBO9781107415324.005, 31-116, 2014.

Jaenicke, R., Dreiling, V., Lehmann, E., Koutsenoguii, P. K., and Stingl, J.: Condensation nuclei at the German Antarctic station "Georg von Neumayer", Tellus B, 44, 311-317, https://doi.org/10.3402/tellusb.v44i4.15459, 1992.

Khlystov, A., Stanier, C., and Pandis, S. N.: An algorithm for combining electrical mobility and aerodynamic size distributions data when measuring ambient aerosol special issue of aerosol science and technology on findings from the fine particulate matter supersites program, Aerosol Sci. Tech., 38, 229-238, https://doi.org/10.1080/02786820390229543, 2004.

König-Langlo, G., King, J. C., and Pettré, P.: Climatology of the three coastal Antarctic stations Dumont d'Urville, Neumayer, and Halley, J. Geophys. Res.-Atmos., 103, 10935-10946, https://doi.org/10.1029/97JD00527, 1998.

Lohmann, U. and Feichter, J.: Global indirect aerosol effects: a review, Atmos. Chem. Phys., 5, 715-737, https://doi.org/10.5194/acp-5-715-2005, 2005.

Massie, S. and Hervig, M.: HITRAN 2012 refractive indices, J. Quant. Spectrosc. Ra., 130, 373-380, https://doi.org/10.1016/j.jqsrt.2013.06.022, 2013.

Minikin, A., Legrand, M., Hall, J., Wagenbach, D., Kleefeld, C., Wolff, E., Pasteur, E. C., and Ducroz, F.: Sulfur-containing species (sulfate and methanesulfonate) in coastal Antarctic aerosol and precipitation, J. Geophys. Res.-Atmos., 103, 1097510990, https://doi.org/10.1029/98JD00249, 1998.

Palmer, K. F. and Williams, D.: Optical constants of sulfuric acid Application to the clouds of Venus, Appl. Optics, 14, 208-219, https://doi.org/10.1364/AO.14.000208, 1975.

Petzold, A. and Schönlinner, M.: Multi-angle absorption photometry - a new method for the measurement of aerosol light absorption and atmospheric black carbon, J. Aerosol Sci., 35, 421-441, https://doi.org/10.1016/j.jaerosci.2003.09.005, 2004.

Petzold, A., Ogren, J. A., Fiebig, M., Laj, P., Li, S.-M., Baltensperger, U., Holzer-Popp, T., Kinne, S., Pappalardo, G., Sugimoto, N., Wehrli, C., Wiedensohler, A., and Zhang, X.-Y.: Recommendations for reporting "black carbon" measurements, Atmos. Chem. Phys., 13, 8365-8379, https://doi.org/10.5194/acp13-8365-2013, 2013.

Pratte, P., Cosandey, S., and Goujon-Ginglinger, C.: A scattering methodology for droplet sizing of ecigarette aerosols, Inhal. Toxicol., 28, 537-545, https://doi.org/10.1080/08958378.2016.1224956, 2016.

Ramanathan, V., Crutzen, P. J., Kiehl, J. T., and Rosenfeld, D.: Aerosols, climate, and the hydrological cycle, Science, 294, 2119-2124, https://doi.org/10.1126/science.1064034, 2001.

Schwartz, S. E.: The Whitehouse effect - short-wave radiative forcing of climate by anthropogenic aerosols: An overview, J. Aerosol Sci., 27, 359-382, https://doi.org/10.1016/00218502(95)00533-1, 1996.
Shepherd, R. H., King, M. D., Marks, A. A., Brough, N., and Ward, A. D.: Determination of the refractive index of insoluble organic extracts from atmospheric aerosol over the visible wavelength range using optical tweezers, Atmos. Chem. Phys., 18, 52355252, https://doi.org/10.5194/acp-18-5235-2018, 2018.

Shettle, E. P. and Fenn, R. W.: Models for the aerosols of the lower atmosphere and the effects of humidity variations on their optical properties, Tech. rep., 1979.

Thompson, D. W. J., Solomon, S., Kushner, P. J., England, M. H., Grise, K. M., and Karoly, D. J.: Signatures of the Antarctic ozone hole in Southern Hemisphere surface climate change, Nat Geosci., 4, 741-749, https://doi.org/10.1038/ngeo1296, 2011.

Toon, O. B., Pollack, J. B., and Khare, B. N.: The optical constants of several atmospheric aerosol species: Ammonium sulfate, aluminum oxide, and sodium chloride, J. Geophys. Res., 81, 57335748, https://doi.org/10.1029/JC081i033p05733, 1976.

Valenzuela, A., Reid, J. P., Bzdek, B. R., and Orr-Ewing, A. J.: Accuracy required in measurements of refractive index and hygroscopic response to reduce uncertainties in estimates of aerosol radiative forcing efficiency, J. Geophys. Res.-Atmos., 123, 64696486, https://doi.org/10.1029/2018JD028365, 2018.

Virkkula, A., Koponen, I. K., Teinilä, K., Hillamo, R., Kerminen, V.-M., and Kulmala, M.: Effective real refractive index of dry aerosols in the Antarctic boundary layer, Geophys. Res. Lett., 33, L06805, https://doi.org/10.1029/2005GL024602, 2006.

Wagenbach, D., Görlach, U., Moser, K., and Münnich, K. O.: Coastal Antarctic aerosol: the seasonal pattern of its chemical composition and radionuclide content, Tellus B, 40, 426-436, https://doi.org/10.3402/tellusb.v40i5.16010, 1988.

Weller, R. and Jurányi, Z.: Aerosol size distribution between 16 and $950 \mathrm{~nm}$ at Neumayer III station during the year 2017, PANGAEA, https://doi.org/10.1594/PANGAEA.899429, 2019a.

Weller, R. and Jurányi, Z.: Aerosol size distribution between 90 and $5000 \mathrm{~nm}$ at Neumayer III station during the year 2017, PANGAEA, https://doi.org/10.1594/PANGAEA.899430, 2019b.

Weller, R., Wöltjen, J., Piel, C., Resenberg, R., Wagenbach, D., König-Langlo, G., and Kriews, M.: Seasonal variability of crustal and marine trace elements in the aerosol at Neumayer station, Antarctica, Tellus B, 60, 742-752, https://doi.org/10.1111/j.1600-0889.2008.00372.x, 2008.

Weller, R., Minikin, A., Wagenbach, D., and Dreiling, V.: Characterization of the inter-annual, seasonal, and diurnal variations of condensation particle concentrations at Neumayer, Antarctica, Atmos. Chem. Phys., 11, 13243-13257, https://doi.org/10.5194/acp-11-13243-2011, 2011.

Weller, R., Minikin, A., Petzold, A., Wagenbach, D., and König-Langlo, G.: Characterization of long-term and seasonal variations of black carbon (BC) concentrations at Neumayer, Antarctica, Atmos. Chem. Phys., 13, 1579-1590, https://doi.org/10.5194/acp-13-1579-2013, 2013.

Weller, R., Schmidt, K., Teinilä, K., and Hillamo, R.: Natural new particle formation at the coastal Antarctic site Neumayer, Atmos. Chem. Phys., 15, 11399-11410, https://doi.org/10.5194/acp-1511399-2015, 2015.

Wex, H., Petters, M. D., Carrico, C. M., Hallbauer, E., Massling, A., McMeeking, G. R., Poulain, L., Wu, Z., Kreidenweis, S. M., and Stratmann, F.: Towards closing the gap between hygroscopic growth and activation for secondary organic aerosol: Part 1 - Ev- 
idence from measurements, Atmos. Chem. Phys., 9, 3987-3997, https://doi.org/10.5194/acp-9-3987-2009, 2009.

Wiedensohler, A., Birmili, W., Nowak, A., Sonntag, A., Weinhold, K., Merkel, M., Wehner, B., Tuch, T., Pfeifer, S., Fiebig, M., Fjäraa, A. M., Asmi, E., Sellegri, K., Depuy, R., Venzac, H., Villani, P., Laj, P., Aalto, P., Ogren, J. A., Swietlicki, E., Williams, P., Roldin, P., Quincey, P., Hüglin, C., Fierz-Schmidhauser, R., Gysel, M., Weingartner, E., Riccobono, F., Santos, S., Grüning, C., Faloon, K., Beddows, D., Harrison, R., Monahan, C., Jennings, S. G., O'Dowd, C. D., Marinoni, A., Horn, H.-G., Keck, L., Jiang, J., Scheckman, J., McMurry, P. H., Deng, Z., Zhao, C. S., Moerman, M., Henzing, B., de Leeuw, G., Löschau, G., and Bastian, S.: Mobility particle size spectrometers: harmonization of technical standards and data structure to facilitate high quality long-term observations of atmospheric particle number size distributions, Atmos. Meas. Tech., 5, 657-685, https://doi.org/10.5194/amt-5-657-2012, 2012.
World Meteorological Organisation: WMO/GAW Aerosol Measurement Procedures, Guidelines and Recommendations, World Meteorological Organisation, WMO, 2016.

Zhang, X., Huang, Y., Rao, R., and Wang, Z.: Retrieval of effective complex refractive index from intensive measurements of characteristics of ambient aerosols in the boundary layer, Opt. Express, 21, 17849-17862, https://doi.org/10.1364/OE.21.017849, 2013.

Zieger, P., Aalto, P. P., Aaltonen, V., Äijälä, M., Backman, J., Hong, J., Komppula, M., Krejci, R., Laborde, M., Lampilahti, J., de Leeuw, G., Pfüller, A., Rosati, B., Tesche, M., Tunved, P., Väänänen, R., and Petäjä, T.: Low hygroscopic scattering enhancement of boreal aerosol and the implications for a columnar optical closure study, Atmos. Chem. Phys., 15, 7247-7267, https://doi.org/10.5194/acp-15-7247-2015, 2015. 